\title{
IMPLEMENTASI CORPORATE SOCIAL RESPONSIBILITY (CSR) DALAM MEWUJUDKAN PARIWISATA BERBASIS MASYARAKAT BERKELANJUTAN
}

\author{
Ni Wayan Juniari ${ }^{1}$, Luh Putu Mahyuni ${ }^{2}$ \\ ${ }^{1}$ Program Studi Akuntansi, Universitas Pendidikan Nasional (Undiknas) \\ Email: niwayanjuniari19@yahoo.com \\ ${ }^{2}$ Program Studi Akuntansi, Universitas Pendidikan Nasional (Undiknas) \\ Email: mahyuniluhputu@undiknas.ac.id
}

Masuk : 02-03-2020, revisi: 03-04-2020, diterima untuk diterbitkan : 09-04-2020

\begin{abstract}
ABSTRAK
Peningkatan kunjungan wisatawan ke suatu destinasi wisata selain membawa manfaat positif juga meninggalkan dampak negatif. Peran manajer sangat signifikan untuk memastikan operasional perusahaan pengelola destinasi wisata dapat mendukung perekonomian masyarakat lokal dan tidak merusak lingkungan, sehingga terwujud praktik bisnis berkelanjutan. Penelitian ini bertujuan mengeksplorasi bagaimana corporate social responsibility (CSR) dipraktikkan untuk dapat mewujudkan pariwisata berbasis masyarakat berkelanjutan. Untuk mencapai tujuan penelitian, penelitian kualitatif dengan pendekatan studi kasus dilakukan di kawasan wisata Monkey Forest Ubud, Gianyar, Bali. Berlandaskan pada konsep CSR dan pariwisata berbasis masyarakat, data dikumpulkan melalui wawancara kemudian dianalisis secara kualitatif dengan bantuan software NVivo12. Penelitian ini mengindikasikan bahwa Monkey Forest Ubud mengimplementasikan berbagai bentuk CSR yang memungkinkan masyarakat lokal berpartisipasi penuh dalam operasional kawasan wisata dan memperoleh manfaatnya secara langsung. Penelitian ini memberikan inspirasi mengenai bagaimana suatu destinasi/kawasan wisata dapat mengimplementasikan CSR untuk memastikan terwujudnya bisnis berkelanjutan dan pada saat bersamaan berkontribusi bagi pengembangan pariwisata berbasis masyarakat berkelanjutan.
\end{abstract}

Kata Kunci: Corporate Social Responsibility, Pariwisata Berbasis Masyarakat Berkelanjutan

\begin{abstract}
Increasing tourist arrivals in a touristic area, besides bringing positive impacts also leaving negative footprints. The role of managers is significant to ensure that the business operational supports the local community and preserve the environment, so as sustainable business can be attained. This study aims at exploring how corporate social responsibility (CSR) is practiced to develop sustainable community-based tourism. To address the research objective, a qualitative case study was conducted at Ubud Monkey Forest, Gianyar, Bali. Guided by the concept of CSR and community-based tourism, data was collected through interviews and analyzed qualitatively with the help of NVivo12 software. This research indicates that Ubud Monkey Forest implements various CSR activities that allow the local community to participate in the operational of the forest and obtain the benefits from the operational. This research exemplifies how a tourist destination could implement CSR to ensure business sustainability and at the same time contribute to the development of sustainable community-based tourism.
\end{abstract}

Keywords: Corporate Social Responsibility, Sustainable Community-Based Tourism

\section{PENDAHULUAN}

\section{Latar belakang}

Pada saat ini, industri pariwisata menjadi salah satu obyek pendapatan terbesar dan menjadi salah satu sektor yang dapat mengembangkan perekonomian masyarakat Bali. Ubud adalah salah satu destinasi wisata favorit yang terletak di Kabupaten Gianyar. Salah satu daya tarik kawasan wisata yang ramai dikunjungi wisatawan ketika berlibur ke Ubud adalah Monkey Forest Ubud. Daya tarik kawasan wisata Monkey Forest Ubud ini yaitu terdapatnya ratusan monyet yang menghuni hutan tersebut dan terdapat juga berbagai macam pohon yang tumbuh dan merindangi kawasan wisata Monkey Forest Ubud. Kunjungan wisatawan ke kawasan wisata Monkey Forest Ubud per harinya antara 3.000 sampai 4.000 orang. Pada bulan Juli hingga Agustus kunjungan wisatawan mengalami peningkatan signifikan (Antara, 2018). 
Meningkatnya kunjungan wisatawan ke Monkey Forest Ubud memberikan dampak positif terhadap masyarakat lokal. Pendapatan asli daerah (PAD) desa setempat mengalami peningkatan. Masyarakat lokal di sekitar Monkey Forest Ubud, baik sebagai pemilik maupun pekerja usaha pendukung pariwisata, seperti vila, hotel, spa, kafe, restauran, toko dan sebagainya, juga merasakan peningkatan pendapatan karena meningkatnya kunjungan wisatawan ke Monkey Forest Ubud.

Di balik berbagai manfaat positif meningkatnya kunjungan wisatawan ke kawasan wisata Monkey Forest Ubud, terdapat beberapa dampak negatif yang tak terelakkan, antara lain kemacetan lalu lintas dan polusi kendaraan bermotor serta peningkatan volume sampah. Untuk mengoptimalkan manfaat positif dan meminimalisir dampak negatif operasional perusahaan, praktik Corporate Social Responsibility (CSR) dipercaya dapat menjadi solusi.

Penelitian-penelitian terkait implementasi CSR sudah cukup banyak dilakukan sebelumnya tetapi masih sedikit yang mengaitkan CSR dengan pariwisata berbasis masyarakat berkelanjutan. Suriany (2008) berpendapat bahwa masyarakat lokal perlu diberdayakan agar sektor pariwisata dapat menjadi andalan bagi pemasukan devisa negara. Salah satu upaya yang dapat dilakukan yaitu dengan melibatkan bisnis yang memiliki kepedulian dan kesukarelaan terhadap persoalan yang ada dan sering dikenal sebagai Corporate Social Responsibility (CSR).

Mengingat terdapatnya pelibatan masyarakat dalam perencanaan, pengorganisasian dan pengembangan kawasan wisata, model pariwisata berbasis masyarakat berkelanjutan dipandang sebagai salah satu solusi ideal untuk mengatasi dampak negatif mass tourism sekaligus menjadikan model ini sebagai strategi untuk memastikan sebagian besar manfaat pariwisata kembali kepada masyarakat lokal (López-Guzmán et al., 2011). Akan tetapi, dalam tataran pelaksanaannya masih terdapat beberapa persoalan yang memunculkan keraguan akan efektivitas model pariwisata berbasis masyarakat berkelanjutan bagi upaya peningkatan perekonomian masyarakat lokal. Persoalan tersebut antara lain, terbatasnya kapabilitas teknis masyarakat setempat dalam pengelolaan kawasan wisata secara profesional (López-Guzmán et al., 2011), terbatasnya sumber dana yang dimiliki yang seringkali membuat kawasan wisata yang dikembangkan masyarakat kurang mampu bersaing dengan pemodal besar (Blackstock, 2005).

Mengingat besarnya potensi manfaat pariwisata berbasis masyarakat berkelanjutan bagi pengembangan perekonomian masyarakat lokal, sangat disayangkan masih sedikit penelitian empiris yang dilakukan untuk mengeksplorasi bagaimana model pariwisata berbasis masyarakat berkelanjutan diterapkan, apa saja kendala yang dihadapi dalam penerapannya (López-Guzmán et al., 2011), bagaimana CSR dapat diterapkan untuk mendukung terwujudnya pariwisata berbasis masyarakat berkelanjutan. Penelitian ini diharapkan dapat mengisi gap dalam literatur dengan memberikan bukti empiris mengenai bagaimana model pariwisata berbasis masyarakat berkelanjutan diterapkan pada konteks negara berkembang, seperti Indonesia. Selain itu, penelitian ini juga melengkapi penelitian-penelitian sebelumnya yang khusus meneliti mengenai CSR (Budiasni, Atmadja and Nyoman Trisna Herawati, 2015; Dianti and Mahyuni, 2018; Dwiyanti and Mahyuni, 2018; Marnelly, 2012) maupun yang khusus meneliti mengenai pariwisata berbasis masyarakat berkelanjutan (Timothy, 1999; Suriany, 2008; Dewi, Fandeli and Baiquni, 2013; Murdiyanto, 2011; Nawawi, 2013), dengan memperluas eksplorasi implementasi CSR dalam kaitannya untuk mewujudkan pariwisata berbasis masyarakat berkelanjutan. Dengan demikian, penelitian ini bertujuan untuk mengeksplorasi implementasi CSR dalam mewujudkan pariwisata berbasis masyarakat berkelanjutan di Kawasan Wisata Monkey Forest Ubud. 


\section{Rumusan masalah}

Bagaimanakah implementasi CSR dalam mewujudkan pariwisata berbasis masyarakat berkelanjutan di Kawasan Wisata Monkey Forest Ubud?

\section{Kajian literatur}

CSR adalah konsep tentang tindakan yang dilakukan oleh perusahaan sebagai bentuk tanggung jawab perusahaan terhadap sosial maupun lingkungan sekitar di mana perusahaan itu didirikan (Pertiwi dan Ludigdo, 2013). CSR dilakukan dengan tujuan untuk menjaga hubungan perusahaan dengan lingkungan sehingga tercipta pembangunan dan bisnis yang berkelanjutan. Perkembangan CSR menyebabkan dunia bisnis yang dulunya hanya berorientasi pada keuntungan (profit), kini juga telah memperhatikan kesejahteraan manusia (people), serta keseimbangan dengan alam semesta (planet).

Kotler dan Lee (2005) membagi kegiatan CSR atas 6 kategori yaitu:

a. Cause Promotions, yaitu suatu bentuk perusahaan yang mengarahkan promosi dan dananya untuk mengembangkan perhatian masyarakatnya terhadap isu sosial untuk mendukung dan berpartisipasi secara sukarela dalam suatu kegiatan tertentu.

b. Cause-Related Marketing, yaitu suatu bentuk komitmen perusahaan agar dapat menyisihkan sejumlah persentase tertentu dari total pendapatannya untuk dana konstribusi dan donasi untuk kegiatan amal yang dapat meningkatkan pemasaran atas produk yang bernilai khusus.

c. Corporate Social Marketing yaitu suatu bentuk CSR yang bertujuan untuk dapat mengubah perilaku masyarakat agar meningkatkan kesehatan, keselamatan publik, menjaga kelestarian alam, serta meningkatkan kesejahteraan masyarakat melalui kampanye yang diselenggarakan oleh suatu perusahaan.

d. Corporate Philanthropy yaitu pemberian sumbangan/kontribusi secara langsung yang dilakukan oleh perusahaan kepada masyarakat tertentu yang membutuhkan dalam bentuk uang tunai, paket bantuan, pemberian beasiswa maupun berupa pelayanan secara cumacuma.

e. Community Volunteering yaitu suatu aktivitas perusahaan guna mendukung dan mendorong para karyawan, rekan pedagang eceran atau para pemegang franchise untuk dapat meluangkan waktu mereka secara sukarela membantu organisasi-organisasi masyarakat lokal maupun masyarakat yang menjadi sasaran program.

f. Socially Responsible Business Practice yaitu suatu aktivitas bisnis perusahaan yang melampaui aktivitas bisnis yang diatur oleh hukum serta melaksanakan investasi yang mendukung kegiatan sosial untuk meningkatkan kesejahteraan komunitas masyarakat dan memelihara lingkungan hidup.

Pengimplementasi program CSR dapat diartikan sebagai kegiatan atau aktivitas perusahaan dalam menerapkan tata kelola perusahaan yang baik (Good Coporate Governance) terhadap aspek lingkungan, ekonomi, dan sosial. Dianti dan Mahyuni (2018) menemukan bahwa praktik CSR masih sebatas tanggung jawab moril perusahaan terhadap masyarakat sekitar yang termotivasi dari dorongan internal perusahaan untuk berbagi. Sedangkan Pertiwi dan Ludigdo (2013) berpendapat bahwa CSR sangat penting dilaksanakan pelaku bisnis pariwisata untuk meminimalisir dampak negatif bisnis yang dijalankan. CSR juga digunakan sebagai strategi untuk menjaga hubungan harmonis dengan masyarakat sekitar (Dwiyanti \& Mahyuni, 2018). Suriany (2008) menemukan bahwa CSR dapat diimplementasikan dalam bentuk pemberdayaan masyarakat lokal dalam pengelolaan pariwisata. 
Pariwisata berbasis masyarakat adalah salah satu jenis pariwisata dimana partisipasi masyarakat (sebagai pemilik maupun pengelola) menjadi unsur utama dalam pariwisata dengan tujuan untuk memberikan manfaat sebesar-besarnya bagi masyarakat setempat (Goodwin \& Santilli, 2009), serta untuk terwujudnya pembangunan pariwisata yang berkelanjutan (Dangi \& Jamal, 2016; López-Guzmán et al., 2011; Telfer, David J., 2007). Partisipasi masyarakat dapat dilakukan dengan dua cara yaitu, ikut terlibat dalam proses pengambilan keputusan dan pembagian manfaat pariwisata. Pelibatan masyarakat setempat dalam pengembangan suatu kawasan wisata diharapkan dapat memberi manfaat antara lain berupa: 1. Dampak ekonomi langsung bagi masyarakat yang bekerja pada kawasan wisata maupun bagi mereka yang membuka usaha pendukung di sekitar kawasan wisata; 2 . Terbentuknya interaksi yang lebih baik dan alami antara masyarakat sekitar sebagai pendukung utama kawasan wisata dengan para pengunjung; 3 . Peningkatan kesadaran dan kepedulian masyarakat setempat dalam menjaga kelestarian lingkungan alam pada kawasan wisata (López-Guzmán et al., 2011).

Goodwin dan Santilli (2009) mengidentifikasi beberapa indikator kesuksesan penerapan model pariwisata berbasis masyarakat berkelanjutan, antara lain: 1. Dampak terhadap pengembangan perekonomian masyarakat lokal; 2 . Kontribusi bagi penurunan angka kemiskinan pada daerah di mana kawasan wisata dikembangkan; 3. Kontribusi bagi penurunan angka pengangguran daerah setempat; 4. Koneksi pasar yang luas yang memungkinkan diraihnya jumlah pengunjung yang memadai dan stabil untuk menjamin keberlangsungan usaha dalam jangka panjang. Untuk mencapai kesuksesan dalam pengelolaan kawasan wisata berbasis masyarakat, beberapa kendala yang umum dihadapi dalam tataran pelaksanaan seperti, kelemahan kapabilitas pengelolaan (López-Guzmán et al., 2011) dan keterbatasan modal (Blackstock, 2005), perlu diatasi terlebih dahulu.

\section{METODE PENELITIAN}

Untuk mencapai tujuan penelitian, metode penelitian kualitatif dengan pendekatan studi kasus diterapkan. Data dikumpulkan dengan melakukan wawancara mendalam secara langsung dengan lima partisipan kunci yang diyakini memiliki pemahaman memadai dan informasi yang dibutuhkan untuk membantu menjawab pertanyaan penelitian. Partisipan tersebut adalah: kepala desa adat Padangtegal, general manager Monkey Forest Ubud, koordinator umum lembaga desa, dan masyarakat lokal maupun masyarakat luar yang berada atau bekerja di sekitar kawasan wisata. Adapun pertanyaan yang diajukan antara lain: 1. Bagaimana model pengelolaan kawasan wisata Monkey Forest Ubud? Mohon dijelaskan; 2. Apakah Monkey Forest Ubud mempraktekkan CSR? Mohon dijelaskan; 3. Bagaimana CSR dirumuskan untuk mendukung terwujudnya pariwisata berbasis masyarakat berkelanjutan? Mohon dijelaskan; 4. Apakah terdapat kendala dalam pengelolaan Monkey Forest Ubud? Mohon dijelaskan.

Data kemudian dianalisis dengan metode Miles and Huberman yang terdiri atas tiga tahapan, yaitu: reduksi data, penyajian data, kesimpulan dan verifikasi (Sugiyono, 2017) dengan bantuan software NVivo12. Triangulasi teknik dan sumber data diterapkan untuk memeriksa keabsahan dan memperkaya data. Prinsip anonimitas diterapkan dalam penelitian ini sebagai upaya mendapatkan informasi jujur dan sebenarnya dari informan. Dengan terlebih dahulu mendapatkan penjelasan bahwa nama mereka tidak akan muncul dalam analisis maupun laporan penelitian, diharapkan tendensi untuk menyembunyikan atau melebih-lebihkan informasi untuk tampak lebih baik dari kondisi sebenarnya, akan dapat dihindari (Grimm, 2010). Informan kemudian diberikan kode I1 sampai dengan I5 dalam proses analisis dan pembahasan. 


\section{HASIL DAN PEMBAHASAN}

Monkey Forest Ubud merupakan salah satu kawasan wisata konservasi yang sangat disakralkan dan dikelola langsung oleh masyarakat Desa Adat Padangtegal yang dalam operasionalnya dimandatkan kepada Kepala Desa Adat Padangtegal. Dalam pengelolaannya, kawasan wisata ini dilindungi dan diatur dalam aturan adat dan kesepakatan adat Desa Adat Padangtegal serta dikelola oleh manajemen profesional dimana seluruh karyawannya merupakan masyarakat Desa Adat Padangtegal dan tetap berada dibawah pengawasan dari Pengurus Desa Adat Padangtegal.

Kawasan wisata Monkey Forest Ubud adalah kawasan wisata yang menerapkan konsep community-based tourism (CBT) didukung dengan adanya peraturan yang mengatur kawasan ini yaitu dalam Keputusan Kepala Desa Adat Padangtegal Nomor: 11/DPP/2012 pasal 1 Tentang "Manajemen Mandala Suci Wanara Wana Desa Adat Padangtegal" yang berbunyi: "Mandala Suci Wenara Wana adalah kawasan suci Desa Adat Padangtegal yang diwarisi oleh Desa Adat Padangtegal secara turun-temurun dan Mandala Suci Wenara Wana perlu dikelola dengan baik sehingga dapat memberikan kesejahteraan kepada warga Desa Adat Padangtegal" (Peraturan Mandala Suci Wenara Wana Desa Pakraman Padangtegal, Ubud, 2014).

Berdasarkan hal tersebut, maka hasil yang diperoleh dari kawasan wisata Monkey Forest Ubud itu disalurkan kembali kepada masyarakat Desa Adat Padangtegal melalui program-program yang dibuat oleh lembaga desa. Program tersebut kemudian dituangkan dalam beberapa bagian yaitu 'Parahyangan' (hubungan manusia dengan Tuhan), 'Pawongan' (hubungan dengan sesama manusia) dan 'Palemahan' (hubungan manusia dengan alam) yang kemudian dijabarkan secara lebih detail dalam pelaksanaannya.

Praktik CSR yang dilaksanakan oleh Monkey Forest Ubud dibuat dan direncanakan oleh lembaga desa melalui program-program desa. Dalam praktiknya program CSR tersebut dibuat dengan tujuan untuk kesejahteraan para pemangku kepentingan terkait. Pariwisata berbasis masyarakat yang diterapkan di Monkey Forest Ubud melibatkan masyarakat lokal atau masyarakat Desa Adat Padangtegal dalam pengelolaannya. Jadi dapat dikatakan bahwa Monkey Forest Ubud dikelola dengan prinsip dari, oleh dan untuk masyarakat. Hasil pengelolaan kawasan wisata dinikmati oleh masyarakat melalui program-program yang telah direncanakan oleh desa. Prinsip pengelolaan ini diterapkan sebagai upaya menciptakan pariwisata yang inklusif dan berkelanjutan, sebagaimana dinyatakan oleh informan I3, “.....dalam pengelolaannya kita berpedoman kepada prinsip pariwisata berkelanjutan, bukan pariwisata sesaat, dengan cara melibatkan semua elemen masyarakat anggota desa adat secara aktif sesuai dengan bidang kompetensinya”. Pernyataan ini didukung oleh informan I1, “...sudah pasti, karena program yang dibuat juga untuk kesejahteraan masyarakat itu sendiri dan juga untuk keberlangsungan kawasan wisata”. Informan I2, I4 dan I5 menyampaikan pendapat senada "......yang jelas semua berupaya mewujudkan pariwisata berbasis masyarakat yang berkelanjutan”.

Penerapan CSR dalam mewujudkan pariwisata berbasis masyarakat berkelanjutan yang dilaksanakan di Monkey Forest Ubud telah mampu menciptakan pengelola kawasan, lembaga desa dan masyarakat lokal yang mandiri dan berdaya untuk membangun daerahnya sendiri. Berikut ini merupakan uraian lebih rinci atas implementasi praktik CSR yang dilaksanakan di Monkey Forest Ubud: 


\section{Implementasi praktik CSR di bidang sosial}

Implementasi praktik CSR di bidang sosial yang dilakukan antara lain berupa bantuan langsung tunai kepada masyarakat (BLT) dan beasiswa. BLT adalah pemberian uang tunai kepada masyarakat dan 'pengayah' (pengurus desa, lembaga desa, pemimpin agama, sie upacara keagamaan). BLT dianggarkan sebanyak 7\% setiap tahunnya dari keuntungan Monkey Forest Ubud. Dari dana 7\% tersebut, sebanyak 5\% diberikan kepada 670 kepala keluarga dan 2\% diberikan kepada 'pengayah' sejumlah 270 orang dengan cara dibukakan rekening di LPD dan dana ditransfer langsung ke rekening masing-masing.

Selanjutnya beasiswa ada dua yaitu beasiswa akademik dan non akademik. Beasiswa akademik dianggarkan 200 juta rupiah untuk diberikan kepada 20 orang mahasiswa/i terbaik yang sedang menempuh pendidikan S1/D3 dengan melalui proses seleksi dari desa dengan persyaratan antara lain keaktifan dalam organisasi 'Sekaa Teruna Teruni' (STT) - organisasi kepemudaan, memiliki prestasi IPK minimal 3,25 untuk 2 semester terakhir, dan sebagainya. Sedangkan beasiswa non akademik diberikan untuk tingkat SD sampai dengan perguruan tinggi dengan melampirkan fotocopy piagam 2 tahun terakhir. Beasiswa akademik dan non akademik diberikan setiap satu tahun sekali yaitu pada saat rapat akhir tahun (RAT) LPD.

\section{Implementasi praktik CSR di bidang lingkungan}

Implementasi praktik CSR di bidang lingkungan dilakukan untuk menjaga keberlangsungan kawasan wisata yang dimiliki. Bentuknya antara lain berupa perluasan hutan dan penanaman pohon. Perluasan hutan pada kawasan Monkey Forest Ubud yaitu 4 Hektar dari yang sebelumnya pada tahun 2003 adalah 8,5 Hektar menjadi 12,5 Hektar.

Implementasi praktik CSR di bidang lingkungan selanjutnya ialah pengadaan mobil shuttle dan penyediaan sentral parkir. Pengadaan mobil shuttle ini bertujuan untuk mengatasi kemacetan yang sering terjadi di wilayah Ubud. Operasional shuttle dimulai pada pukul 07.00 hingga pukul 22.00 dengan 11 pos pemberhentian shuttle dan jangka waktu keberangkatan setiap 15 menit sekali. Jumlah shuttle yang dimiliki saat ini adalah 6 buah, dimana 3 buah merupakan milik desa dan 3 buah lagi merupakan CSR dari Bank BPD dan BNI. Bahan bakar yang digunakan shuttle adalah solar dan untuk penggunaan shuttle boleh untuk siapa saja, tidak dikenakan biaya atau tarif. Sedangkan penyediaan sentral parkir tujuannya untuk mengatasi kemacetan dan mengatasi parkir-parkir liar. Pada sentral parkir tersebut juga dibangun sarana olahraga untuk memberi wahana bagi masyarakat menjaga kesehatannya dengan berolahraga.

Praktik CSR di bidang lingkungan lainnya adalah berupa pembentukan rumah kompos yang dibentuk untuk pengelolaan sampah dari masyarakat Desa Adat Padangtegal. Rumah kompos ini dibentuk sejak tahun 2012 dengan memberikan tempat sampah untuk setiap kepala keluarga dan menerapkan sistem pemilahan sampah antara sampah organik dan non organik. Sejak tahun 2015 telah diterapkan 'perarem' - aturan adat, kalau sampah tidak dipilah maka sampah tersebut tidak akan diangkut. Untuk saat ini rumah kompos masih belum melaksanakan pengelolaan limbah bahan beracun dan berbahaya (B3) dan untuk sementara limbah B3 masih dikategorikan sebagai sampah non organik. Rumah kompos merencanakan akan bekerja sama dengan pihak ketiga untuk menangani limbah B3, karena limbah B3 sendiri memerlukan penanganan khusus. Apabila limbah B3 masih memiliki nilai jual, seperti aki, maka pihak rumah kompos akan menjualnya, tetapi apabila tidak memiliki nilai jual, limbah B3 tersebut masih dibuang ke tempat pembuangan akhir (TPA). Tahun 2018 Desa Adat Padangtegal mendirikan tempat pembuangan sampah terpadu (TPST), yang merupakan satu-satunya TPST yang ada di Bali, yang mengelola dan mengedukasi masyarakat di bidang pelestarian lingkungan. 


\section{KESIMPULAN DAN SARAN}

Kawasan wisata Monkey Forest Ubud adalah kawasan wisata yang dikelola dengan konsep community-based tourism atau pelibatan masyarakat lokal dalam pengelolaan pariwisata. Kawasan wisata ini dikelola dengan prinsip dari, oleh dan untuk masyarakat, untuk memastikan terciptanya kemandirian ekonomi masyarakat lokal dalam mengelola kawasannya. Dalam pengelolaannya, kawasan wisata Monkey Forest Ubud telah mempraktikkan beberapa program CSR untuk menciptakan kesejahteraan masyarakat dan mewujudkan pariwisata berbasis masyarakat berkelanjutan. Praktik CSR tersebut telah diterapkan dalam 2 bidang, yaitu:

a. Di bidang sosial yaitu berupa pemberian bantuan lansung tunai (BLT) dan beasiswa.

b. Di bidang lingkungan berupa perluasan hutan, penanaman pohon, penyediaan shuttle, sentral parkir, dan rumah kompos.

Penelitian ini memberikan bukti empiris akan penerapan model pengelolaan kawasan wisata berbasis masyarakat berkelanjutan yang menjamin manfaat pariwisata dapat dinikmati sebesarbesarnya untuk kepentingan masyarakat setempat dengan tetap menjamin lestarinya lingkungan alam. Penelitian ini diharapkan dapat menjadi bahan masukan bagi pemerintah setempat maupun pemerintah daerah lain di Indonesia dalam merumuskan kebijakan terkait perencanaan dan penataan kawasan wisata.

Adapun saran yang dapat diberikan sebagai bahan pertimbangan evaluasi bagi pengelola kawasan wisata dan pemerintah setempat adalah sebagai berikut:

1. Bahan bakar untuk shuttle yang masih mempergunakan bahan bakar solar, sebaiknya diganti menggunakan listrik sehingga lebih ramah lingkungan.

2. Peranan pemerintah sangat dibutuhkan dalam mendukung penertiban parkir-parkir liar untuk menunjang keberhasilan Monkey Forest dalam membuatkan sentral parkir guna mengatasi kemacetan.

3. Diperlukan kerjasama yang baik antara pihak pemerintah, pengelola kawasan wisata dan masyarakat sekitar dalam penanganan limbah B3. Pemerintah setempat diharapkan dapat menyusun dan menegakkan aturan terkait penanganan limbah B3, melakukan sosialisasi lebih intensif kepada masyarakat dan pengelola kawasan wisata dalam penanganan limbah B3. Pemerintah setempat dapat pula mempertimbangkan opsi memberi kesempatan kepada pihak ketiga dengan kompensasi tertentu dalam penanganan limbah B3 jika kemampuan mengelola sendiri belum dimiliki.

\section{REFERENSI}

Antara. (2018). Monkey Forest Ubud Itu Keajaiban. https://bali.antaranews.com/berita/133568/dpr-monkey-forest-ubud-itu-keajaiban

Blackstock, K. (2005). A critical look at community based tourism. Community Development Journal, 40(1), 39-49. https://doi.org/10.1093/cdj/bsi005

Budiasni, N. W. N., Atmadja, A. T., \& Nyoman Trisna Herawati. (2015). Implementasi Corporate Social Responsibility Berdasarkan Konsep Tri Hita Karana (Studi Kasus Hotel Como Shambala Estate Di Banjar Begawan Kecamatan Payangan Kabupaten Gianyar). JIMAK, 3(1).

Dangi, T. B., \& Jamal, T. (2016). An integrated approach to "sustainable community-based tourism." Sustainability (Switzerland), 8(5). https://doi.org/10.3390/su8050475

Peraturan Mandala Suci Wenara Wana Desa Pakraman Padangtegal, Ubud, (2014).

Dewi, M. H. U., Fandeli, C., \& Baiquni, M. (2013). Pengembangan Desa Wisata Berbasis Partisipasi Masyarakat Lokal di Desa Wisata Jatiluwih Tabanan, Bali. Jurnal Kawistara, $3(2), 117-226$. 
Dianti, G. P., \& Mahyuni, L. P. (2018). Praktik Corporate Social Responsibility ( CSR ) pada Interkontinental Bali Resort Hotel: Eksplorasi Berbasis Tri Hita Karana. Jurnal Ilmiah Akuntansi Dan Bisnis, 3(1), 12-22.

Dwiyanti, N. K. A. L., \& Mahyuni, L. P. (2018). PENERAPAN CORPORATE SOCIAL RESPONSIBILITY ( CSR ) PADA INDUSTRI PERHOTELAN : STUDI KASUS PADA THE TANJUNG BENOA BEACH RESORT. Jurnal Ilmiah Akuntansi Dan Bisnis, 3(2), 153-160. http://journal.undiknas.ac.id/index.php/akuntansi/article/view/2119

Goodwin, H., \& Santilli, R. (2009). Community-Based Tourism : a success? Tourism Management, 1-37.

Grimm, P. (2010). Social Desirability Bias. In Willey International Encyclopedia of Marketing. Wiley Inc. https://doi.org/https://doi.org/10.1002/9781444316568.wiem02057

Kotler, P., \& Lee, N. (2005). Corporate Social Responsibility: Doing the Most Good for Your Company and Your Cause. John Wiley \& Sons, Inc.

López-Guzmán, T., Sánchez-Cañizares, S., \& Pavón, V. (2011). Community - based tourism in developing countries: A case study. Tourismos, 6(1), 69-84.

Marnelly, T. R. (2012). Corporate Social Responsibility (CSR): Tinjauan Teori Dan Praktek Di Indonesia. Jurnal Aplikasi Bisnis, 2(2), 49-59.

Murdiyanto. (2011). Partisipasi Masyarakat Dalam Pengembangan Desa Wisata Karanggeneng, Purwobinangun, Pakem, Sleman. SEPA: Jurnal Sosial Ekonomi Pertanian Dan Agribisnis, $7(2)$.

Nawawi, A. (2013). Partisipasi Masyarakat Dalam Pengelolaan Wisata Pantai Depok Di Desa Kretek Parangtritis. Jurnal Nasional Pariwisata, 5(2), 103-109.

Pertiwi, I. D. A. E., \& Ludigdo, U. (2013). Implementasi Corporate Social Responsibility Berlandaskan Budaya Tri Hita Karana. Jurnal Akuntansi Multiparadigma. https://doi.org/10.18202/jamal.2013.12.7208

Sugiyono. (2017). Metode Penelitian Kuantitatif, Kualitatif dan $R \& D$. Alfabeta.

Suriany, L. (2008). Penerapan Corporate Social Responsibility dengan Konsep Community

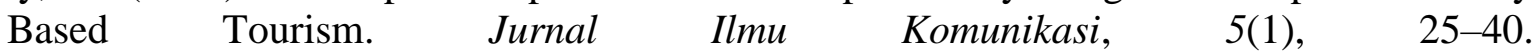
https://doi.org/https://doi.org/10.24002/jik.v5i1.216

Telfer, David J., and R. S. (2007). Tourism and Development in the Developing World. (1st Edition). Routledge. https://doi.org/10.4324/9780203938041

Timothy, D. J. (1999). Participatory Planning a View of Tourism in Indonesia. Annals of Tourism Research, 26(2), 371-391. 